\title{
Erratum: Cyclic hardening in bundled actin networks
}

\author{
K.M. Schmoller, P. Fernández, R.C. Arevalo, D.L. Blair \& A.R. Bausch
}

Nature Communications 1:134 doi: 10.1038/ncomms1134 (2010); Published 7 Dec 2010; Updated 7 Feb 2012.

This Article contains two typographical errors in the first paragraph of the Results section. The phrase 'decreases from $\sim 12 \mathrm{~Pa}$ to less than $\sim 14 \mathrm{~Pa}$ ' should read 'decreases from $\sim 12 \mathrm{~Pa}$ to less than $\sim 4 \mathrm{~Pa}$ ' and 'a continuous decrease of the linear stiffness to $\sim 12 \mathrm{~Pa}$ ' should read 'a continuous decrease of the linear stiffness to $\sim 2 \mathrm{~Pa}$ '. 